\title{
The Effects of a Brief Touch Point Intervention for Children With Intellectual Developmental Disabilities (IDD)
}

\author{
Matthias Grünke ${ }^{1}$, Karolina Urton ${ }^{2} \&$ Jennifer Karnes ${ }^{1}$ \\ ${ }^{1}$ Department of Special Education \& Rehabilitation, University of Cologne, Germany \\ ${ }^{2}$ Department of Educational Science, University of Paderborn, Germany \\ Correspondence: Matthias Grünke, Ph.D., Department of Special Education \& Rehabilitation, University of \\ Cologne, Klosterstr. 79b, Cologne, Northrhine-Westfalia, 50931, Germany, Tel: 0049-221-4705547. E-mail: \\ matthias.gruenke@uni-koeln.de
}

Received: August 17, 2018 Accepted: September 24, 2018 Online Published: September 28, 2018

doi:10.5539/jedp.v8n2p187 URL: http://doi.org/10.5539/jedp.v8n2p187

\begin{abstract}
This single-case study evaluated the impact of a brief touch point intervention on the ability of three third graders with intellectual developmental disabilities (IDD) to perform single-digit additions. A multiple-baseline (AB)-across-participants design was used to establish a cause-and-effect relationship between an intervention of 13 to 15 one-on-one teaching sessions and the expected outcome. Results indicated that all three students benefited from the treatment and showed increased performance of their addition skills over the course of the B Phase. By the end of the intervention, the average improvement rates varied from 164.50 to $420.00 \%$. The findings are discussed in light of the existing literature, and conclusions are drawn.
\end{abstract}

Keywords: addition skills, educational inclusion, intellectual developmental disabilities, touch point intervention

\section{Introduction}

In Western societies, children and youth with so-called intellectual developmental disabilities (IDD) comprise around $1.5 \%$ of the population of their peers (Salvador-Carulla, \& Bertelli, 2008). IDD has become an umbrella diagnosis for a range of genetic and neurological disorders "that are characterized by cognitive limitations and difficulties in practical, social, and conceptual domains" (Brown, Lunsky, Dennis, \& Vigod, 2016, p. 714). Present at birth, these disorders negatively affect the ability to learn, reason, and problem solve. Well-known types of IDD include Fragile X Syndrome, Down Syndrome, and Prader-Willi Syndrome (Guastaferro \& Lutzker, 2018). Significant subaverage intellectual functioning usually co-occurs with deficits in communicative and interactional skills (Schalock, Luckasson, \& Shogren, 2007). Both the magnitude of the cognitive delays and the restricted capability to demonstrate adaptive behavior put individuals with IDD at high risk for social isolation. The participation and inclusion of individuals with IDD in their community is, therefore, a major area of concern (Wuang, Ho, \& Su, 2013).

Educating students with IDD in the academic areas that will help them to eventually take part in the labor market, whether sheltered or non-sheltered, and to make an active contribution to their society is one of the key ways to fight social marginalization (Avant \& Heller, 2011). Besides fundamental literacy skills, basic math concepts should be at the core of all deliberate and systematic activities designed to meet essential learning needs (Witzel \& Little, 2016). Acquisition of substantial mathematical computation skills is especially vital because it is not only necessary for gaining and maintaining at least simple employment, but also for handling private affairs like managing one's time, purchasing goods, or managing a bank account (Brown \& Snell, 2000; Cihak \& Foust, 2008).

The basic operations of elementary arithmetic comprise addition, subtraction, multiplication, and division. In order to grasp the idea behind the last three procedures, it is necessary to first master combining two or more numbers to find their sum. The acquisition of addition concepts happens at different stages. According to common information-processing theories with regard to the development of mathematical understanding - like the chronometric approach (Ashcraft, 1982), the cognitive perspective on addition and subtraction (Fusion, 1988), or the model of children's strategy choices and strategy discoveries (Shrager \& Siegler, 1998) - children count both addends when first learning to solve simple addition problems (count-all strategy). For example, if students have to 
solve a problem like $3+4$, they have to start counting from 1 to 3 and then counting the second summand until they reach 7. Such procedures are often executed with the help of fingers. The second strategy is the count-on strategy whereby the child is able to start counting from the last number of the first summand. For the example of $3+4$, this would mean that 3 is the first spoken number and from that on, the student is counting on the second summand until 7, and the problem is solved. The third strategy - the storing and later retrieving strategy, which seems to be the most difficult for children struggling with basic mathematical facts - fundamental additions are memorized and can be retrieved quickly as required. This strategy is crucial in order to proceed to the next higher computational level. If children have automated the basic facts, they will need less time to solve problems, commit fewer errors, and relieve their working memory (Carpenter \& Moser, 1984; Geary, 2007).

Students who fail to acquire basic addition skills will not be able get to the heart of subtraction, multiplication, and division, and as long as they struggle with basic operations of elementary arithmetic, they will break down when it comes to solving more advanced problems. As a result, and due to heavy demands on their working memory, these students hang on to rather simple, ineffective, and error-prone strategies (like guessing or finger counting). Conversely, if they have received proper training of basic skills, learners show a greater ability to apply higher mathematical skills while becoming more active in general (Butler, Miller, Lee, \& Pierce, 2001; Cihak \& Foust, 2008).

When teaching students with IDD basic addition skills, representational strategies, coupled with frequent feedback, explicit instruction, and intense drill and practice, seem to be especially helpful (Butler et al., 2001; Mastropieri, Bakken, \& Scruggs, 1991). One such representational approach is called touch points and traces back to Kramer and Krug, who in 1973 published an article entitled "A rationale and procedure for teaching addition." The two authors outlined a dot-notation approach, in which numbers are depicted with corresponding touch points. Whereas the numbers 1 to 5 use single touch points, the numbers 6 to 9 use double touch points, illustrated by dots within circles.

Using this method, learners are explicitly taught to tap on the points and count aloud. The number "1" involves one tap, "2" involves two taps, and so on. Thus, the first step is supporting the development of quantitative understanding as well as number meaning. The second step is to solve single-digit addition facts by using the counting-all strategy plus tapping the dots. Subsequently, the students learn to count-on after first choosing the bigger summand and counting on, tapping the second one. This strategy may be used not only to solve single-digit additional facts but also double-digit addition problems, subtraction, multiplication, and division. One of the great advantages of the concept is its multisensory nature; that is, stimulating haptic (touching the dots), auditory (counting out loud), and visual (watching the dots on the digits) senses (Scott, 1993).

Based on Kramer and Krug's (1973) concept, Bullock, Pierce, and McClellan (1989) designed a sequential curriculum program with detailed materials for different arithmetic problems, called TouchMath (see www.touchmath.com). Most of the research that has been conducted on the effectiveness of dot-notation approaches has focused on various versions of the commercial TouchMath program. For example, in his systematic literature review, Aydemir (2015) analyzed 27 published and unpublished studies on the benefits of this technique. More than half of the subjects in these experiments were children or youth with special needs, mostly with learning disabilities. For every study that focused on teaching addition skills to students with different kinds of IDD, the authors chose a single-case design. In all instances, the outcomes were positive.

The results of Aydemir (2015) were backed up by Ellingsen and Clinton (2017), who summarized the findings related to the effectiveness of TouchMath from eight published single-case analyses and two group experiments, all of them focused on students with various types of disabilities. Not surprisingly, since Ellingsen and Clinton (2017) examined publications that were part of the earlier review by Aydemir (2015), they drew similar conclusions concerning the usefulness of this technique.

Both reviews speak to the value of TouchMath programs for supporting students with special needs (including those with IDD) in understanding fundamental arithmetic operations and building fluency in this area. With one exception, the interventions were implemented in the United States, relied on commercial materials, and stretched over several weeks. As such, they do not meet the widely accepted standards for single-subject research proposed by Horner, Carr, Halle, McGee, Odom, and Wolery (2005) that studies must be replicated across multiple geographical locations and focus on practical as well as cost-effective treatments in order for their findings to have a high level of external and social validity.

Thus, the purpose of the present study was to attempt to meet Horner et al.'s (2005) criteria by examining the effects of a rather brief and simple touch point intervention consisting of self-made materials delivered for a maximum duration of 15 days with three students with IDD in an inclusive elementary school in Germany. We 
decided to select relatively young participants of between 8 and 10 years of age, and focus on teaching them how to master single-digit addition problems. In consideration of the aforementioned information-processing theories and the findings about the effects of TouchMath, we expected a gradual increase in the performance of our participants, not a sudden performance leap.

\section{Method}

\subsection{Participants and Setting}

The subjects were three third graders (Note 1) (two boys and one girl), Abbas, Beni, and Caro (names changed for anonymity), who attended an inclusive elementary school in a major city in Northrhine-Westfalia (Germany) with an enrollment of approximately 200 students and programs for children with special needs in grades 1 to 4 . They were selected using the following inclusion criteria: (a) diagnosed with an IDD by a multi-professional team, (b) received special education services at least one hour each day, (c) were able to count to 10 or beyond, but demonstrated only rudimentary addition skills, (d) were absent less than five school days during the previous two months, and (e) had sufficient motivation to participate in the training. We consulted the teachers of the school during a faculty meeting to identify students eligible for our intervention.

Abbas. Abbas was 8;11 years old at the time of the study. His parents had moved to Germany from Turkey before he was born. He had microcephaly (a medical condition in which the brain does not develop properly, resulting in a smaller-than-normal head) and expressive as well as receptive speech disorders. His classroom teacher described him as a curious, but very reserved boy.

Beni. Beni was 9;10 years old at the time of the study; and did not have an immigrant background. As an infant, he was diagnosed with the Koolen de Vries Syndrome, a rare genetic disorder that is characterized by developmental delays in different cognitive areas. His classroom teacher portrayed him as motivated to learn, but easy to distract.

Caro. Caro was 9;6 years old when the study began and did also not have a migration background. She had been diagnosed with the Prader-Willi Syndrome, a genetic disorder due to loss of function of specific genes, that often leads to intellectual impairment. Her teacher described her as enthusiastic, but also as very attention seeking.

We were not able to gain access to the three participants' current IQ scores. However, at the time of their school enrollment, their IQ varied between 55 and 65 .

\subsection{Materials}

We used a number of materials as part of the study. For the assessment, we constructed a pool of 36 math problems in which two single-digit numbers (excluding 0 values) had to be added to find a single-digit sum $(1+8=, 1+7=$, $1+6=, \ldots 2+7=, 2+6=, 2+5=, \ldots 3+6=, 3+5=, 3+4=, \ldots)$. Out of this pool, we generated $188 \times 12$ " worksheets, each consisting of 10 math problems (we made sure that no grouping of exercises contained the same math problem more than once). The items were equally difficult. For example, the problem $1+1$ looks much easier to solve than $3+5$ or $4+3$. However, by making sure that the expected sums varied between 2 and 9 in each worksheet, we tried to alleviate this issue.

For the intervention, we created $3 \times 5$ " white note cards, each with a numeral from 1 through 9 printed on it. The numbers on half of the cards displayed the dot notation system as outlined in Bergman (2014). Furthermore, we used cards with the plus and the equal sign on it. The numerals, the plus as well as the equal sign, and the dots were all printed in black. Lastly, we developed a pool of $6 x 8$ " worksheets, each containing one addition problem of the form $a+b=$ ?. The maximum sum could never exceed 9. A third of the worksheets had touch points on both numerals, a third had touch points only on the second addend, and a third did not have touch points on any of the numbers.

\subsection{Dependent Variables and Measurement}

The dependent variable was the number of correctly solved addition problems per worksheet. Thus, scores could differ between 0 and 10. During daily probes, participants were given 5 minutes to finish a worksheet. After the time was up, the worksheets were collected, and the scores were checked. Reliability of measurement was calculated by having the math probe sheets independently reviewed by two observers: the interventionist (see below) and a student assistant. The interrater agreement equaled $100 \%$.

\subsection{Experimental Design and Procedure}

We applied an AB single-case multiple-baseline design across students (Kazdin, 2010) to evaluate the benefits of the touch point intervention. According to Kratochwill et al. (2010), the minimum number of measurements in a baseline is three. We staggered the zero points of the intervention, starting with Abbas after the third, Beni after the 
fourth, and Cora after the fifth baseline probe. The study was spread over 18 school days (three and a half weeks).

A 25-year-old female graduate student of special education served as the interventionist. She had been instructed in the use of the dot notation concept by the first author during three one-hour sessions. In addition, she familiarized herself thoroughly with the basic tenets of the approach by studying Bergman (2014), Bullock et al. (1989), and other sources on touch points, as well as reviewing the YouTube videos produced by Innovative Learning Concepts Inc. (see https://www.youtube.com/channel/UCap5UH5fQG0DLBAyYkLh_Eg). We deliberately chose a person as an interventionist who cannot be considered a particularly experienced educator, because we wanted to demonstrate that the training is even usable by someone without extensive expert knowledge. Assessment and instruction occurred during the regular school day in the second block period between 10.15 and 11.50 a.m. $-\mathrm{a}$ time reserved for independent course activities.

During baseline, the interventionist administered the math probes to participants individually after time lags of 20 minutes. Whereas the measurement conditions stayed the same in the intervention phase, the participants no longer engaged in independent coursework, but were instead taught how to perform simple additions by using the touch point method. Specifically, the interventionist worked with each child for 20 minutes every day to make the principles of the multisensory program and the basis for addition accessible to them. After finishing with one child, she spent 5 minutes administering the math probes, before moving on to the next one. The order in which she attended to the students varied from day to day.

The treatment followed the basic principles of explicit instruction, including (a) modelling of the targeted behavior(s), (b) guided and independent practice, and (c) corrective feedback (Stein, Kinder, Silbert, Carnine, \& Rolf, 2017). In the first three sessions, the interventionist explicitly taught the students the dot positions of the numbers 1 through 9 on the index cards. She went through them one-by-one in numerical order, touching the points while counting out loud in a certain sequence, and having the participants repeat the procedure. As soon as the children mastered this step, the interventionist moved on to modeling simple additions with small numbers $(1,2$, and 3). She used the cards to generate addition problems (e.g., $1+1=, 2+2=, 3+1=, \ldots$ ) and solved them by counting the dots while thinking out loud. The participants were asked to repeat what the interventionist had just modeled while solving a particular problem. In case a student needed help, assistance was offered. At the end of the third lesson, the children were asked to finish three to six worksheets with problems that involved small numbers $(1,2,3)$ with dots printed on them. The interventionist provided guidance where necessary.

The following five sessions were designated to instructing the children on how to use the count-on strategy for addition with our materials. This involved (a) stating the problem aloud, (b) stating the first addend aloud, (c) counting the dots on the second number aloud (starting from the first addend), and (d) repeating the problem aloud with the answer. The interventionist used index cards with numerals that had dots printed on them to come up with different math problems. She began with additions involving only small numbers and continued until all of the numerals were included. While performing the last step of the strategy ("repeating the problem aloud with the answer"), the index card with the correct sum was always placed next to the other cards on the table.

As time went by, the interventionist used more and more cards for the first addend with no points printed on them. Just as during the first three sessions, she modeled the targeted behavior before the children were encouraged to perform it themselves with as little assistance as necessary. At the end of each session, the participants finished five to eight worksheets that had touch points only on the second addend.

The remaining sessions were reserved for building fluency in addition. Every math problem was first solved by utilizing cards with touch points for the second addend (the card with the first addend continued to be one without points). As soon as the count-on strategy had been executed and both the problem and the correct result had been stated, a card with dots was replaced by one without dots, whereupon the problem and the result were restated. Again, the interventionist modeled the behavior, and the children were expected to solve the problems with continuously less and less assistance. The end of each session was marked by participants trying to solve 10 math problems with worksheets of the last category (including numerals with no touch points on them). Throughout the treatment, the interventionist provided frequent verbal praise for active participation as well as for every correct response.

\subsection{Treatment Fidelity}

To enhance faithful delivery of the training, we provided the interventionist with a detailed script to follow. In addition, the first author stayed in close contact with her, at least twice a week, through email or phone to check if everything was implemented according to the plan. The main teacher objected to the option of having a student assistant sit in during each session to fill out a checklist covering the basic features of the treatment. Thus, we were 
not able to use any formal measures of adherence to the intervention guidelines.

\section{Results}

\subsection{Visual Analysis}

As shown in Figure 1, Abbas' performance during baseline was poor, never exceeding two correctly solved math problems. Upon the onset of the intervention, it took a couple of days before a clear upward trend was noticeable. However, he was able to boost his performance and reach the high score of 10 during four out of the last five measurements.

Beni showed a relatively unstable baseline with a stark drop in correctly solved math problems from Probe 2 to Probe 3. When the intervention was first implemented, his performance declined from 3 to 2 to 0 points, but subsequently he was able to increase his score until he reached 9 on the last day of the treatment.

Caro earned between 0 and 3 points during baseline. After the intervention began, she increased the number of correctly solved addition problems from 2 to 5, but dropped back to 2 at Probe 8. From this time onward, however, she demonstrated a perceptible increase in performance until she reached the high score of 10 at the end of the touch point training.

In sum, all three students responded well to the treatment and ended up with very high scores (9 or 10). However, the intervention did not lead to an immediate change in the behavior. Instead, it took a couple of days until improvements became transparent.
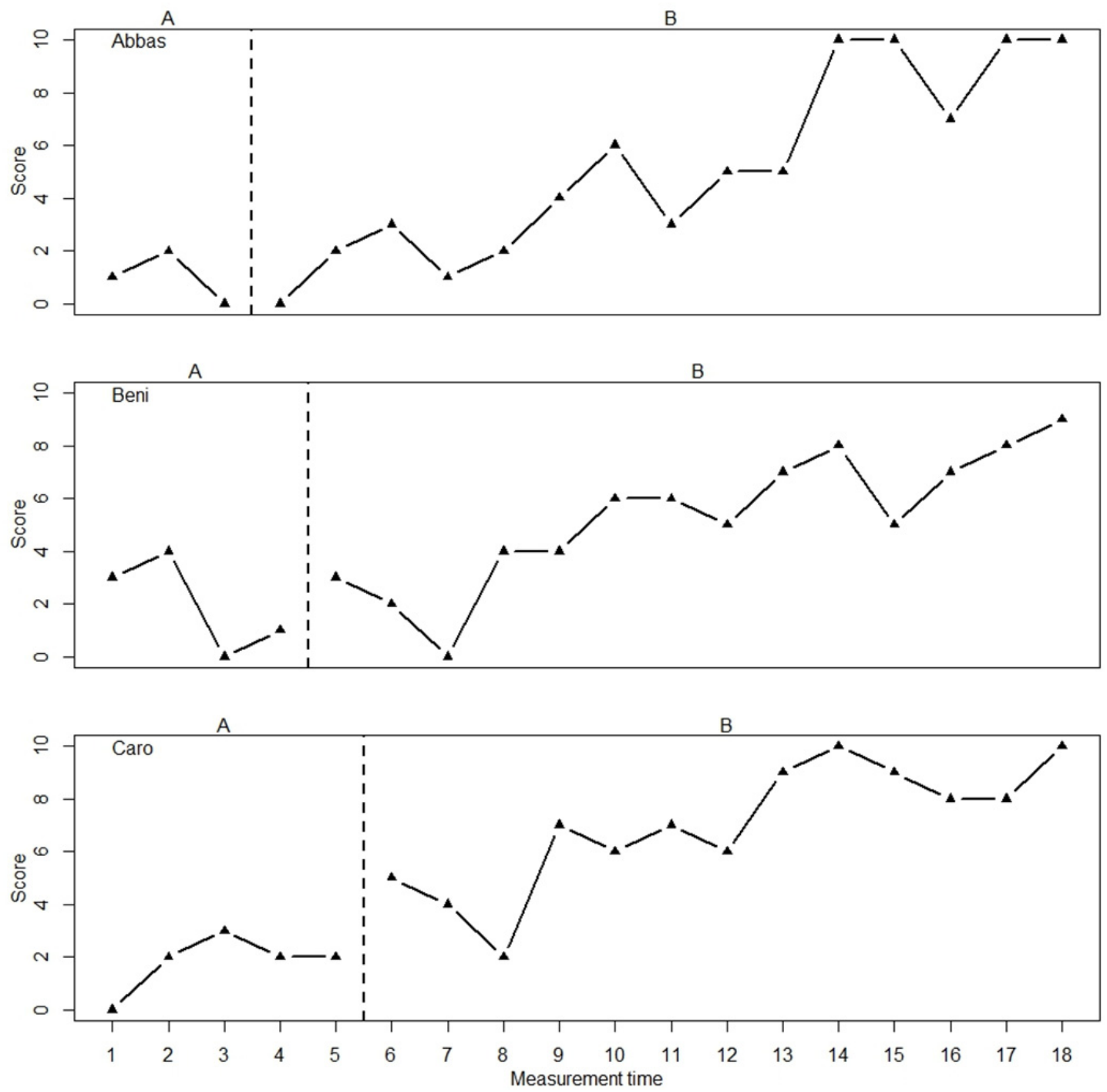

Figure 1. Number of correctly solved addition problems 


\subsection{Quantitative Analysis (Note 2)}

Descriptive statistics for the number of correctly solved addition problems for each participant are presented in

Table 1. In all cases, performance rose from A to B. Abbas increased his average number of points by $420.00 \%$, Beni by $164.50 \%$, and Caro by $288.89 \%$.

Table 1. Descriptive statistics for correctly solved addition problems

\begin{tabular}{lllllllllllll}
\hline & $N$ & & $M$ & & $M d$ & & $\min$ & & $\max$ & \multicolumn{2}{c}{$S D$} & A \\
\hline Name & A & B & A & B & A & B & A & B & A & B & A \\
\hline Abbas & 3 & 15 & 1.00 & 5.20 & 1.00 & 5.00 & 0 & 0 & 2 & 10 & 1.00 & 3.51 \\
Beni & 4 & 14 & 2.00 & 5.29 & 2.00 & 5.50 & 0 & 0 & 4 & 9 & 1.83 & 2.52 \\
Caro & 5 & 13 & 1.80 & 7.00 & 2.00 & 7.00 & 0 & 2 & 3 & 10 & 1.10 & 2.38 \\
\hline
\end{tabular}

The next step in the analysis involved calculating some of the most common non-overlap effect sizes (see Table 2). To that end, we calculated the percentage of non-overlapping data (PND), the percentage of data points exceeding the median (PEM), the percentage of data points exceeding the median trend (PET), the percentage of all non-overlapping data (PAND), pairwise data overlap (PDO), improved rate difference (IRD), and Tau-U. From the arious options for computing Tau- $\mathrm{U}$, we selected the one that not only combines non-overlap between phases with trend from within the intervention phase, but also controls for baseline trend (A vs. B. $\left.+\operatorname{trend}_{\mathrm{B}}-\operatorname{trend}_{\mathrm{A}}\right)($ Parker, Vannest, \& Davis, 2014; Parker, Vannest, Davis, \& Sauber, 2011).

Table 2. Overlap indices for correctly solved addition problems

\begin{tabular}{llllllll}
\hline & PND & PEM & PET & PAND & PDO & IRD & Tau-U \\
\hline Abbas & 73.33 & 86.67 & 100.00 & 83.33 & 84.44 & 0.53 & 0.75 \\
Beni & 64.29 & 85.71 & 100.00 & 77.78 & 82.14 & 0.54 & 0.71 \\
Caro & 92.31 & 92.31 & 92.31 & 88.89 & 93.85 & 0.92 & 0.68 \\
\hline
\end{tabular}

All of the aforementioned non-overlap effect sizes have both strengths and weaknesses, and there is no consensus in the scientific community on which procedure is best. For a comprehensive review of these approaches, we refer to the special issues of the Journal of Counseling and Development in 2015 (issue 4), Journal of School Psychology in 2014 (issue 2), Neuropsychological Rehabilitation in 2014 (issues 3 and 4), and Remedial and Special Education in 2017 (issue 6). Overall, the effect sizes (see Table 2) supported the high potency of the touch point intervention.

Furthermore, we conducted a piecewise regression analysis for each student (level 1 analysis) (Huitema \& McKean, 2000). Since we used rather short baselines of three, four, and five measurements, respectively, it is difficult to determine whether a Phase A trend existed or not. Under such circumstances, any statistical test to identify a baseline trend has only very limited power. This raises the risk of committing a beta error (the null hypothesis of no Phase A trend is false, but is not rejected). However, a visual inspection of the three baselines suggests that no upward trend existed before the intervention started. Abbas' three baseline data points showed an increase in performance from Probe 1 to Probe 2 and a decrease from Probe 2 to Probe 3. Beni's values indicated an increase, a stark decrease, as well as an increase, respectively. Finally, Caro's data exhibited two increases, one decrease, and a tie.

Thus, we decided to conduct our piecewise regression analysis without the assumption of the existence of Phase A trends. However, because our presupposition about the non-presence of baseline trends rested on rather subjective evaluations of very few data points, our results can only be interpreted with caution. 
Table 3. Piecewise regression model for number of correctly solved addition problems (Level 1 Analysis)

\begin{tabular}{llllll}
\hline & $B$ & $S E$ & $t$ & $p$ & $R^{2}$ \\
\hline Intercept & Abbas & & & & \\
Level & 1.00 & 0.86 & 1.17 & .026 & .23 \\
Slope & -1.49 & 1.18 & -1.26 & $>02$ \\
\hline & 0.71 & 0.09 & 8.02 & $>.01$ & 0.65 \\
Intercept & Beni & & & & \\
Level & 2.00 & 0.73 & 2.75 & .02 & 0.01 \\
Slope & -0.60 & 1.10 & -0.55 & .59 & 0.48 \\
\hline & 0.52 & 0.10 & 5.39 & $>.01$ & \\
Intercept & Caro & & & & .01 \\
Level & 1.80 & 0.61 & 2.93 & .11 & 0.03 \\
Slope & 1.74 & 1.02 & 1.71 & $>.01$ & 0.26 \\
\hline
\end{tabular}

As the findings in Table 3 indicate, all three participants showed a significant slope effect. This implies that the students did not demonstrate a sudden increase in performance, but got progressively better at solving single-digit addition problems over the course of the intervention.

To supplement the previous data analyses, we generated an across-case Tau-U (A vs. B $+\operatorname{trend}_{B}-\operatorname{trend}_{A}$ ), which yielded an index of 0.71. Such an overall effect size is generally considered as large (Parker \& Vannest, 2009; Vannest \& Ninci, 2015). In addition, we conducted a hierarchical piecewise linear-regression analysis by aggregating all three single cases into one (level 2 analysis) in accordance with the procedures outlined by Wilbert (2018) (see also Grünke, Wilbert, \& Calder Stegemann, 2013).

Table 4. Piecewise regression model for the aggregated three single cases (Level 2 Analysis)

\begin{tabular}{llllll}
\hline & $B$ & $S E$ & $d f$ & $t$ & $p$ \\
\hline Intercept & 1.53 & 0.63 & 49 & 2.43 & .02 \\
Level & -0.09 & 0.65 & 49 & -0.14 & .89 \\
Slope & 0.58 & 0.06 & 49 & 10.26 & $>.01$ \\
\hline
\end{tabular}

The data presented in Table 4 imply that the treatment brought about a significant increase in the ability to solve one-digit math problems in all three participants; thus, confirming the previously presented level 1 analysis.

\section{Discussion}

\subsection{Main Findings}

The purpose of this study was to investigate whether elementary-age students ( 8 to 10 years old) with IDD would benefit from a brief touch point intervention for solving simple addition tasks with a single-digit sum. Our findings indicate that the dot-notation approach described in this paper was very effective at enhancing the participants' ability to solve this type of math problems. As we expected, the intervention did not lead to an immediate behavior change. It took a couple of days for the students' improvements to become visible. This may be explained by the fact that they had to gradually develop more and more insights into the process of combining two numbers to find their sum and more automaticity in solving simple addition problems. Any irregularities in the curve progressions may be attributed to varying task difficulties and changing motivational states. However, the overall results document that the three children were able to improve their performance many times over (Abbas: $420.00 \%$, Beni: $164.50 \%$, Caro: $288.89 \%$ ). Particularly noteworthy here is that these effects became apparent although the intervention with a maximum duration of 15 days was rather short. Hence, we were able to confirm the heartening results from previous studies (see Aydemir, 2015; Bergman, 2014; Ellingsen \& Clinton, 2017) with a small sample of three third graders with IDD in a German school setting. 


\subsection{Limitations}

As with all empirical studies, this single-subject analysis exhibits certain limitations. First, it suffers from the same weakness as all case reports: lack of generalizability due to the small sample size. In addition, we neglected to collect follow-up data. Thus, we can only hope that the treatment effects are stable through time. Another limitation pertains to the way the starting points of the treatment were determined. Ideally, a randomization procedure is included in the design when assigning measurement times to conditions (Kratochwill \& Levin, 2010). However, we staggered the introduction of the intervention systematically.

The limited generalizability of our study can be modified by multiple replications of experiments with samples that originate from the population about which one wants to make inferences. Fortunately, the body of research on the effectiveness of touch point interventions is comparatively large. Thus, our findings do not stand alone, but add a small meaningful piece to an existing puzzle. Collecting follow-up data and including a randomization procedure would have helped to enhance the validity of an experiment. Yet, what is desirable is not always feasible under practical conditions in the classroom. Specifically, in the current study, school holidays made it impossible for us to continue data collection. Hence, we are not able to provide information on the stability of the treatment results through follow-up measurements. However, considering findings from previous research on the benefits of touch point interventions (e.g. Calik \& Kargin, 2010) we can assume that maintenance of the training effects is achievable through regular refresher lessons. Regrettably, the classroom teacher objected to us applying a randomization procedure, but wanted us to set starting points for the intervention that differed only by-a-day. It would have certainly enhanced the internal validity of our experiment had we been given the opportunity to determine the beginning of the training for each participant by chance, but this was not for us to decide.

An additional limitation is that the treatment fidelity was not checked by any formal measures of adherence to the intervention guidelines during the examination. This would have been important, as the interventionist had limited experience in implementing our dot-notation approach. Finally, with regard to the selection of the sample, it should be critically noted that we did not carry out our own examination of the students' IQ. Furthermore, we conducted the study with a very heterogeneous group of students with IDD. Nevertheless, our results still support the findings of previous investigations that a touch point intervention has a positive effect on solving mathematical problems irrespective of a particular diagnosis within the range of IDD (Aydemir, 2015; Bergman, 2014; Ellingsen \& Clinton, 2017).

\subsection{Practical Implications and Future Research}

The results of our study show that both resource-saving and effective support is possible with a simple touch point intervention. Unlike the commercial materials of TouchMath, the cost of developing our worksheets and note cards was very low. However, in order to be able to provide tailored interventions for very diverse learners under everyday conditions in school, self-made touch point worksheets and note cards cannot offer the same possibilities as the vast variety of different TouchMath materials professionally produced by an established educational publishing house. Teachers need to consider different arguments regarding expenditures and benefits when deciding which materials to obtain and use in order to provide legitimate support for diverse learners as they try to acquire basic arithmetic skills.

Anyway, the results of our study provide encouraging evidence that touch points can be effectively used to improve simple addition skills in elementary school students with IDD with little costs and little time involved. Anecdotal feedback by the three students indicated that they all enjoyed the intervention very much and that they were happy about their improvements, supporting the assumption that a touch point intervention like ours is not only potent, but also has ample social validity.

As mentioned earlier, our study could have gained in explanatory power if we had incorporated randomization procedures into the design and monitored the treatment fidelity more closely. Whenever possible, both aspects should be considered in future research. Beyond that, the long-term effects of brief touch point interventions should be examined. This is of specific relevance for children with IDD, as these students demonstrate particular problems in building up fact knowledge that is accessible in the long run (Guastaferro \& Lutzker, 2018). If the previous effects of the application of touch points are also confirmed under long-term conditions, it makes sense to transfer basic mathematical skills to practical areas of life, such as calculation with money.

Our experiment was conducted under everyday conditions in school. However, applying the treatment in the way we described was only possible with the assistance of a graduate student who attended to the children on a one-on-one basis. Future research should focus on investigating options for how to impart arithmetic through touch points individually to students when no additional interventionist is available. First and foremost, the 
effectiveness of peer-tutoring should be explored (Bowman-Perrott, Burke, Zhang, \& Zaini, 2014; Bowman-Perrott, Davis, Vannest, Williams, Greenwood, \& Parker, 2013; Ginsberg-Block, Rohrbeck, \& Fantuzzo, 2006; Grünke, Saddler, Asaro-Saddler, \& Moeyaert, in press; McMaster, Fuchs, \& Fuchs, 2006). Applying a system of instruction in which students help each other and learn by teaching seems to be realizable with sufficient briefings and well-elaborated materials like the ones that exist for TouchMath. In addition, the use of computer-assisted dot-notation approaches should be explored.

Since mathematical skills go beyond addition, as mentioned by Aydemir (2015), future investigations should also examine the effectiveness of touch point interventions in the acquisition of mathematical operations such as subtraction, multiplication, and division.

\section{References}

Aydemir, T. (2015). A review of the articles about TouchMath. Procedia-Social and Behavioral Sciences, 174, 1812-1819. https://doi.org/10.1016/j.sbspro.2015.01.842

Bergman, S. H. (2014). The effectiveness of using TouchMath addition techniques with students with learning disabilities. Retrieved from https://www.touchmath.com/about/researchPapers.cfm?rID=271

Bowman-Perrott, L., Burke, M., Zhang, N., \& Zaini, S. (2014). Direct and collateral benefits of peer tutoring on social and behavioral outcomes: A meta-analysis of single-case research. School Psychology Review, 43, 260-285.

Bowman-Perrott, L., Davis, H., Vannest, K. J., Williams, L., Greenwood, C. R., \& Parker, R. (2013). Academic benefits of peer tutoring: A meta-analytic review of single-case research. School Psychology Review, 42, 39-55.

Brown, F., \& Snell, M. E. (2000). Instruction of students with severe disabilities. Upper Saddle River, NJ: Prentice Hall.

Brown, H. K., Lunsky, Y., Dennis, C. L., \& Vigod, S. (2016). Perinatal health of women with intellectual and developmental disabilities and comorbid mental illness. The Canadian Journal of Psychiatry, 61, 714-723. https://doi.org/10.1177/0706743716649188

Bullock, J., Pierce, S., \& McClellan, L. (1989). TouchMath. Colorado Springs, CO: Innovative Learning Concepts.

Butler, F. M., Miller, S. P., Lee, K., \& Pierce, T. (2001). Teaching mathematics to students with mild-to-moderate mental retardation: A review of the literature. Mental Retardation, 39, 20-31. https://doi.org/10.1352/0047-6765(2001)039\%3C0020:TMTSWM\%3E2.0.CO;2

Carpenter, T. R., \& Moser, J. M. (1984). The acquisition of addition and subtraction concepts in grades one through three. Journal of Research in Mathematics Education, 15, 179-202. https://doi.org/10.2307/748348

Calik, N. C., \& Kargin, T. (2010). Effectiveness of the TouchMath technique in teaching addition skills to students with intellectual disabilities. International Journal of Special Education, 25, 195-204.

Cihak, D. F., \& Foust, J. L. (2008). Comparing number lines and touch points to teach addition facts to students with autism. Focus on Autism and Other Developmental Disabilities, 23, 131-137. https://doi.org/10.2307/748348

Ellingsen, R., \& Clinton, E. (2017). Using the TouchMath program to teach mathematical computation to at-risk students and students with disabilities. Educational Research Quarterly, 41, 15-40.

Fusion, K. C. (1988). Children's counting and concepts of number. New York, NY: Springer.

Geary, D.C. (2007). Development of mathematical understanding. In D. Kuhn, R. S. Siegler, W. Damon, \& R. M. Lerner (Eds.), Handbook of child psychology (pp. 777-810). Hoboken, NJ: Wiley.

Ginsberg-Block, M. D., Rohrbeck, C. A., \& Fantuzzo, J. W. (2006). A meta-analytic review of social, self-concept, and behavioral outcomes of peer-assisted learning. Journal of Educational Psychology, 98, 732-749. https://doi.org/10.1037/0022-0663.98.4.732

Grünke, M., Saddler, B., Asaro-Saddler, K., \& Moeyaert, M. (in press). The effects of a peer-tutoring intervention on the text productivity and completeness of narratives written by eighth graders with learning disabilities. International Journal for Research in Learning Disabilities.

Grünke, M., Wilbert, J., \& Calder Stegemann, K. (2013). Analyzing the effects of story mapping on the reading comprehension of children with low intellectual abilities. Learning Disabilities: A Contemporary Journal, 11, 51-64. https://doi.org/10.1002/9780470147658.chpsy0218 
Guastaferro, K., \& Lutzker, J. R. (2018). A guide to programs for parenting children with Autism Spectrum Disorder, intellectual disabilities or developmental disabilities. London, UK: Jessica Kingsley Publishers.

Horner, R. H., Carr, E. G., Halle, J., McGee, G., Odom, S., \& Wolery, M. (2005). The use of single-subject research to identify evidence-based practice in in special education. Exceptional Children, 71, 165-179. https://doi.org/10.1177/001440290507100203

Huitema, B. E., \& McKean, J. W. (2000). Design specification issues in time-series intervention models. Educational and Psychological Measurement, 60, 38-58. https://doi.org/10.1177/00131640021970358

Kazdin, A. E. (2010). Single-case research designs: Methods for clinical applied settings. Oxford, UK: Oxford University Press.

Kramer, T., \& Krug, D. A. (1973). A rationale and procedure for teaching addition. Education and Training of the Mentally Retarded, 8, 140-145.

Kratochwill, T. R., \& Levin, J. R. (2010). Enhancing the scientific credibility of single-case intervention research: Randomization to the rescue. Psychological Methods, 15, 124-144. https://doi.org/10.1037/14376-003

Kratochwill, T. R., Hitchcock, J., Horner, R. H., Levin, J. R., Odom, S. L., Rindskopf, D. M, \& Shadish, W. R. (2010). Single-case designs technical documentation. Retrieved from http://ies.ed.gov/ncee/wwc/pdf/wwc_scd.pdf.

Mastropieri, M. A., Bakken, J. P., \& Scruggs, T. E. (1991). Mathematics instruction for individuals with mental retardation: A perspective and research synthesis. Education and Training in Mental Retardation, 26, 115-129.

McMaster, K. L., Fuchs, D., \& Fuchs, L. S. (2006). Research on peer-assisted learning strategies: The promise and limitations of peer-mediated instruction. Reading and Writing Quarterly, 22, 5-25. https://doi.org/10.1080/10573560500203491

Parker, R. I., \& Vannest, K. J. (2009). An improved effect size for single-case research: Nonoverlap of all pairs. Behavior Therapy, 40, 357-367. https://doi.org/10.1016/j.beth.2008.10.006

Parker, R. I., Vannest, K. J., \& Davis, J. L. (2014). A simple method to control positive baseline trend within data nonoverlap. Journal of Special Education, 48, 79-91. https://doi.org/10.1177/0022466912456430

Parker, R. I., Vannest, K. J., Davis, J. L., \& Sauber, S. B. (2011). Combining non-overlap and trend for single-case research: Tau-U. Behavior Therapy, 42, 284-299. https://doi.org/10.1016/j.beth.2010.08.006

Salvador-Carulla, L., \& Bertelli, M. (2008). "Mental retardation" or "intellectual disability": Time for a conceptual change. Psychopathology, 41, 10-16. https://doi.org/10.1159/000109950

Schalock, R. L., Luckasson, R. A., \& Shogren, K. A. (2007). The renaming of mental retardation: Understanding the change to the term intellectual disability. Intellectual and Developmental Disabilities, 45, 116-124. https://doi.org/10.1352/1934-9556(2007)45[116:TROMRU]2.0.CO;2

Scott, K. S. (1993). Multisensory mathematics for children with mild disabilities. Exceptionality, 4, 97-111. https://doi.org/10.1207/s15327035ex0402_6

Shrager, J., \& Siegler, R. S. (1998). SCADS: A model of children's strategy choices and strategy discoveries. Psychological Science, 9, 405-410. https://doi.org/10.1111/1467-9280.00076

Stein, M., Kinder, D., Silbert, J., Carnine, D. W., \& Rolf, K. (2017). Direct instruction mathematics. London, UK: Pearson.

Vannest, K. J., \& Ninci, J. (2015). Evaluating intervention effects in single-case research designs. Journal of Counseling \& Development, 93, 403-411. https://doi.org/10.1002/jcad.12038

Wilbert, J. (2018). Package "Scan." from https://www.uni-potsdam.de/fileadmin01/projects/inklusion/scan/scan.pdf

Witzel, B. S. \& Little, M. E. (2016). Teaching elementary mathematics to struggling learners. New York, NY: Guilford.

Wuang, Y.-P., Ho, G.-S., \& Su, C.-Y. (2013). Occupational therapy home program for children with intellectual disabilities: A randomized, controlled trial. Research in Developmental Disabilities, 34, 528-537. https://doi.org/10.1016/j.ridd.2012.09.008 


\section{Notes}

Note 1. In Germany, elementary school starts with grade 1 at age 6 and ends with grade 4 . Thus, grade 1 is equivalent to kindergarten in the United States.

Note 2. All quantitative analyses were conducted using the SCAN package for R by Wilbert (2018).

\section{Copyrights}

Copyright for this article is retained by the author(s), with first publication rights granted to the journal.

This is an open-access article distributed under the terms and conditions of the Creative Commons Attribution license (http://creativecommons.org/licenses/by/4.0/). 